\title{
Quantitative Structure-Activity Relationships and Molecular Docking Studies of P56 LCK Inhibitors
}

\author{
Nagakumar Bharatham, Kavitha Bharatham, and Keun Woo Lee* \\ Division of Applied Life Science, Environmental Biotechnology National Core Research Center: \\ Gyeongsang National University, Jini 660-701. Korea. ${ }^{*}$ E-mail: kwlee@gsnuac.kr. \\ Received October 6. 2005
}

\begin{abstract}
Three-dimensional quantitative structure-activity relationship (3D-QSAR) models were developed for 67 molecules of 2-amino-benzothiazole-6-anilide derivatives against lymphocyte-specific protein tyrosine kinase (P56 LCK). The molecular field analysis (MF $\Lambda$ ) and receptor surface analysis (RSA) were employed for $\mathrm{QS} \wedge \mathrm{R}$ studies and the predictive ability of the model was validated by 15 test set molecules. Structure-based investigations using molecular docking simulation were performed with the crystal structure of P56 LCK. Good correlation between predicted fitness scores versus observed activities was demonstrated. The results suggested that the nature of substitutions at the 2-amino and 6-anilide positions were crucial in endancing the activity, thereby providing new guidelines for the design of novel P56 LCK inhibitors.
\end{abstract}

Key Words : P56 LCK. Protein tyrosine kinase (PTKs), Benzothiazole derivatives, 3D-QSAR, GOLD molecular docking

\section{Introduction}

Protein tyrosine kinases (PTKs) are critically involved in signaling pathways that regulate cell growth, differentiation, activation, and transformation. ${ }^{1-3}$ PTKs can be divided into receptor tyrosine kinases (RTKs) and non-receptor (cytosolic) tyrosine kinases. ${ }^{4,5}$ Typically, a cascade of signals is initiated from an RTK after ligand binding, which leads to receptor dimerization, kinase activation, and autophosphorylation of tyrosine residues. These phosphorylated tyrosines then serve as docking sites for recruiting downstream signaling molecules, including non-receptor tyrosine kinases that can trigger a variety of cell responses.

Lymphocyte-specific protein tyrosine kinase (LCK) is a member of the Src family of non-receptor protein tyrosine kinases, ${ }^{7.8}$ expressed primarily in T-Lymphocytes and natural killer cells. ${ }^{9.10} \mathrm{LCK}$ is essential for T-cell development and function." It is constitutively associated with the cytoplasmic portions of the CD4 and CD8 surface receptors and plays a key role in T-cell antigen receptor (TCR) linked signal transduction pathways. ${ }^{12-1+}$ Inhibitors of LCK may have potential therapeutic ability in the treatment of autoimmune diseases such as coxsackievinus B3-mediated heart diseases, theumatoid arthritis, multiple sclerosis, lupus, as well as inflammatory diseases, prevention of solid organ transplantation and allergic diseases. 15.18

\section{Methods}

Biological Data and Structures. The activity data and two-dimensional structures for 67 benzothiazole analogs were taken from the literature reported by Jagabandhu Das et $\mathrm{cll}^{19.00}$ The activity data and structure of each molecule are listed in Table 1 to Table 4.

3D-QSAR. Three dimensional quantitative structure- activity relationship (3D-QSAR) ${ }^{1 \bumpeq 2}$ models were developed by Molecular Field Analysis (MFA) and Receptor Surface Analysis (RSA) methods using Cerins2 software ${ }^{23}$ on a series of 67 benzothiazole analogs. These 67 molecules were divided into two sets, namely training set of 52 molecules and test set of remaining 15 molecules.

Molecular Structure Generation and Alignments. All the molecules were initially modeled using Molecule Builder module of Cerius 2 software. Molecules were minimized with smart minimizer and further geometric optimizations were performed using MOPAC with the AM1 method. All the molecules were manually aligned to the most active molecule, compound 51 (Table 3) by considering the significant basic scaffold 2-amino-bennzothiazole-6-anilide. Further refinement in the alignment was carried out by a RMS based automated approach.

Molecular Field Analysis (MFA). Molecular field values were generated for all the aligned molecules using $\mathrm{CH} 3$ (steric) and $\mathrm{H}+$ (electrostatic) probes. Only $10 \%$ from the total No. of variables, whose variance is highest, were considered as independent variables. The biological activities of all 52 molecules in the training set were used as the dependent variables (Table 1 to Table 4). Genetic function algorithm (GFA) combined with partial least square (PLS) approach (only linear terms were considered) was used in order to develop a set of QSAR equations. For deriving the MFA QSAR equations, number of compounds in training set are 52, the descriptor values scaled to a variance of 1.0 , the optimal number of components fixed as 3 , the length of the equation set to 6 terms and genetic crossovers limited to 5000 generations.

Receptor Surface Analysis (RSA). The RSA technique builds a hypothetical model of the receptor site that embodies essential information about the receptor in terms of hydrophobicity, charge, electrostatics (ELE) potential, 
Table 1. Training set and test set compounds with observed and predicted activities<smiles>[R]C(=O)Nc1nc2c([R3])cc(C(=O)Nc3ccc([R])cc3)c([R2])c2s1</smiles>

Compound 1-33 (Table 1)<smiles>[R]Nc1nc2ccc(C(=O)Nc3ccc([R])cc3)cc2s1</smiles>

\begin{tabular}{|c|c|c|c|c|c|c|c|}
\hline Compound & $\mathrm{R}$ & Rl & $\mathrm{R} 2$ & $\mathrm{R} 3$ & Exp. plC50" & MFA Pred. plC $50^{h}$ & RSA Pred. plC50 \\
\hline 1 & 2,6-.Me! & NHI-Cyclopropyl & 11 & $1 \mathrm{I}$ & 1.045 & 1.3167 & 1.1784 \\
\hline 2 & $2-\mathrm{Cl}, 6-\mathrm{Mle}$ & $\mathrm{N} I \mathrm{l}-\mathrm{t}-\mathrm{Bu}$ & 11 & lI & 2.398 & 1.7724 & 1.76 \\
\hline 3 & $2,4,6-\mathrm{Me}_{3}$ & Cyclopropyl & 11 & 11 & 1.699 & 1.5966 & 0.9855 \\
\hline 4 & $2-\mathrm{Cl}, 6-\mathrm{Me}$ & 2-Me-cyclopropyl & II & 11 & 2.154 & 2.0169 & 1.775 \\
\hline 5 & $2-\mathrm{Cl}, 6-\mathrm{Me}$ & $\mathrm{NHI}-\left(\mathrm{Cl} \mathrm{I}_{2}\right)_{2}-\mathrm{N}-(\mathrm{Me})_{2}$ & 11 & l1 & 1.522 & 1.3775 & 1.1825 \\
\hline 6 & $2-\mathrm{C} 1,6-\mathrm{Me}$ & $\left.\mathrm{NH}-\mathrm{C}(\mathrm{CH})_{2}\right)_{2}-\mathrm{Cl}_{2} \mathrm{II}_{3}$ & II & 11 & 1.26 & 1.4067 & 1.1824 \\
\hline 7 & $2-\mathrm{C} 1,6-\mathrm{Me}$ & $\mathrm{NI}[-p-\mathrm{F}-\mathrm{PH}$ & II & 11 & 0.91 & 0.489 & 1.17 \\
\hline 9 & $2-\mathrm{Cl}, 6-\mathrm{Me}$ & $\mathrm{NH} l-(x-\mathrm{F} \cdot \mathrm{l}-\mathrm{B}] \mathrm{t}$ & II & 11 & 1.721 & 1.4883 & 1.1826 \\
\hline 10 & $2-\mathrm{Cl} 1,6-\mathrm{Me}$ & NII-CH:-2-Furyl & 11 & 11 & 1.409 & 1.3159 & 1.1492 \\
\hline 11 & $2-\mathrm{Cl}, 6-\mathrm{Me}$ & VH L-Cyclopenty」 & 11 & II & 1.346 & 1.32 .3 & 1.181 \\
\hline 12 & 2,6-.Me: & NHL-I,l-Me-propyl & 11 & lI & 1.097 & 1.4002 & 1.1824 \\
\hline 14 & $2,4,6-\mathrm{Me}_{3}$ & $\mathrm{NI} I-n-\mathrm{Bu}$ & 11 & 11 & 0.481 & 0.3771 & 0.4089 \\
\hline 15 & $2,4,6-\mathrm{Me}_{\mathrm{i}}$ & $\mathrm{O}-t-13 u$ & II & 11 & 0.537 & -0.2007 & 0.1114 \\
\hline 16 & $2,4,6-\mathrm{Me}_{i}$ & $\mathrm{O}-t-13 \mathrm{u}$ & $\mathrm{Cl}$ & II & -0.643 & -0.1927 & -0.0803 \\
\hline 17 & $2,4,6-\mathrm{Me}_{i}$ & $\mathrm{O}-t-13 u$ & II & $\mathrm{CH}_{3}$ & -0.748 & -0.210 .3 & 0.1112 \\
\hline 19 & 2,6-..Me & I-Propyl & II & 11 & -0.255 & -0.2274 & 0.0854 \\
\hline 20 & $2,6-\mathrm{Me}_{2}$ & 2-Me-cyclopropyl & 11 & II & 1.958 & 2.0086 & 1.8 \\
\hline 23 & $2,4,6-\mathrm{Me}_{i}$ & f-Propyl & II & 11 & 0.154 & -0.6474 & -0.6863 \\
\hline 24 & $2-\mathrm{Cl}, 6-\mathrm{Me}$ & Cyclobutyl & II & II & 0.176 & 0.6672 & 0.547 \\
\hline 25 & $2-\mathrm{Cl} 1,6-\mathrm{Me}$ & 2-Tetrahydrofuryl & 11 & 11 & 0.565 & 1.4373 & 0.9635 \\
\hline 26 & $2-\mathrm{Cl} 1,6-\mathrm{Me}$ & $0-\mathrm{Me}-\mathrm{Bn}$ & 11 & 11 & 0.247 & -0.0761 & 1 \\
\hline 27 & $2,4,6-\mathrm{Me}_{i}$ & NHI-Bn & 11 & 11 & -0.238 & 0.4785 & 0.0287 \\
\hline 29 & $2-\mathrm{Br}, 4,6-\mathrm{Me}_{2}$ & $0-t-13 u$ & II & 11 & 0.698 & 0.3443 & 0.1216 \\
\hline 30 & 2,6- $\mathrm{Me}_{2}, 4-\mathrm{COOCl}$ & $0-t-13 u$ & $\mathrm{II}$ & 11 & -0.494 & -0.5965 & -0.1881 \\
\hline 31 & $2,6-\mathrm{Me}_{2}, 4-\mathrm{Br}^{+}$ & $\mathrm{O}-t-13 \mathrm{u}$ & II & 11 & 0.958 & $0.75]$ & 0.2033 \\
\hline 32 & $2,6-\mathrm{Me}_{1}$ & $0-t-13 u$ & II & 11 & 1.045 & 0.888 & 0.8903 \\
\hline 33 & $2-\mathrm{Cl}, 6-\mathrm{Me}$ & $\mathrm{O}-t-13 u$ & 11 & $\mathrm{l}$ & 1.154 & 0.8935 & 0.8903 \\
\hline \multicolumn{8}{|c|}{ TEST SET } \\
\hline 8 & $2-\mathrm{Cl}, 6-\mathrm{Me}$ & $\mathrm{NI} I-p-\mathrm{F}-\mathrm{B} n$ & 11 & II & 1.06 & 1.6005 & 1.1825 \\
\hline 13 & $2,6-\mathrm{Me}_{2}$ & $\mathrm{NII-t-B \textrm {U }}$ & 11 & II & 1 & 1.361 .3 & 1.1805 \\
\hline 18 & $2,6-\mathrm{Me}_{2}$ & Cyclopropyl & 11 & II & 1.823 & 2.0106 & 1.7573 \\
\hline 21 & 2-C $1,6-\mathrm{Me}$ & Cyclopropyl & 11 & II & 2.045 & 2.0187 & 1.735 \\
\hline 22 & $2,6-\mathrm{Me}_{2}, 4-\mathrm{Cl}_{2} \mathrm{OII}$ & $O-t-13 u$ & 11 & $\mathrm{H}$ & 0.508 & -0.423 .3 & 0.1085 \\
\hline 28 & $2,4,6-\mathrm{Me}_{i}$ & NH-Cyclopropyl & 11 & 11 & 0.522 & 0.8812 & 0.4058 \\
\hline
\end{tabular}

"Observed activities. "MFA predicted activities. "RSA predicted activities

van der Waals (VDW) potential and hydrogen-bonding propensity. Variable selection techniques such as GFA along with PLS can then be used to develop a set of QSAR equations that explains the relationship between the activity values and the RSA descriptors such as ELE, VDW at each surface point.

The following parameters were set for deriving the QSAR equations using RSA method. Number of compounds in training set are 52, the descriptor values scaled to a variance of 1.0 , the optimal number of components fixed as 3 , the length of the equation set to 6 terms and genetic crossovers limited to 5000 generations.

Molecular Docking. The program GOLD (Genetic Optimisation for Ligand Docking) from Cambridge Crystallographic Lata Center, UK. ${ }^{24}$ was used to dock the inhibitors into the ATP site of the P56 LCK. GOLD is an automated ligand docking program that uses a genetic algorithm to explore the full range of ligand conformational flexibility with partial flexibility of the protein, and satisfles the fundamental requirement that the ligand must displace loosely bound water on binding. A crystal structure of P56 LCK was used for molecular docking studies (PDB code: 1QPC). ${ }^{25}$ 
Table 2. Training set and test set compounds with observed and predicted activities

\begin{tabular}{|c|c|c|c|c|c|}
\hline Compound & $\mathrm{R}$ & $\mathrm{Rl}$ & Гxp. pIC $50^{\prime \prime}$ & MГА Pred. pIC $50^{\prime \prime}$ & RSA Pred. pIC $50^{\circ}$ \\
\hline 34 & $2,4,6-\mathrm{Mc}_{3}$ & $\mathrm{H}$ & -1.178 & -0.8127 & -1.1527 \\
\hline 37 & $2,4,6-\mathrm{Mc}_{3}$ & 2-Pyrazinyl & 0.628 & 0.4015 & 1.09267 \\
\hline 38 & $2,4,6-\mathrm{Mc}_{3}$ & 3 -(1,2,4-Triazinyl $)$ & -0.276 & -0.3246 & 0.6873 \\
\hline 39 & $2,4,6-\mathrm{Mc}_{3}$ & 4-Pyrimidinyl & 0.394 & 1.2276 & 1.1228 \\
\hline 41 & 2-Cl,6-Mc & 3-Pyrazolyl & -0.201 & 0.3345 & 0.3097 \\
\hline 42 & $2-\mathrm{C}], 6-\mathrm{Mc}$ & $\begin{array}{c}\mathrm{Ph} \\
\text { TEST SET }\end{array}$ & 0.485 & 0.7188 & 0.1379 \\
\hline 35 & $2,4,6-\mathrm{Mc}_{3}$ & 2-Pyridyl & 0.86 & 1.2326 & 1.1743 \\
\hline 36 & $2,4,6-\mathrm{Mc}$ & $\mathrm{Pl}_{3}$ & -0.24 & 0.2722 & -0.6346 \\
\hline 40 & $2-\mathrm{Cl}, 6-\mathrm{Mc}$ & 4-Pyrimidinyl & 1.569 & 1.7662 & 1.7662 \\
\hline
\end{tabular}

"Observed activitics. "MГ $\Lambda$ predicted activities. "RSA predicted activities

Table 3. Training set and test set compounds with observed and predicted activitics
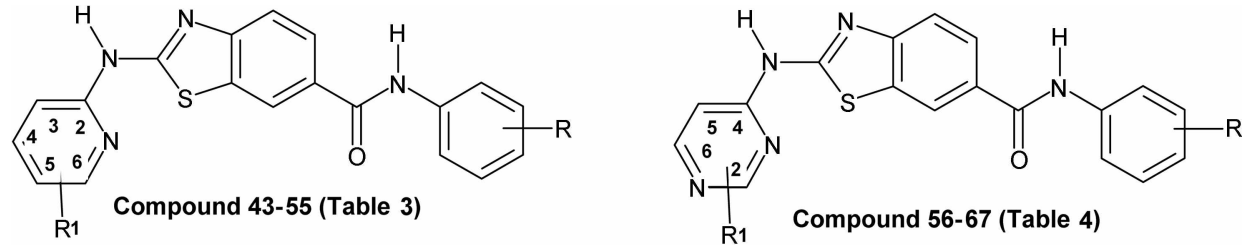

\begin{tabular}{|c|c|c|c|c|c|}
\hline Compound & $\mathrm{R}$ & RI & Exp, plC $50^{4}$ & MFA Pred. ple $50^{l /}$ & RSA Pred. plC50 \\
\hline 43 & $2.4 .6-\mathrm{Mc}_{3}$ & 4-Mc & 1.494 & 1.2262 & 1.1734 \\
\hline 44 & $2.4,6-\mathrm{Mc}_{3}$ & 6-Mc & 0.744 & 1.33 & 1.1957 \\
\hline 46 & $2-\mathrm{Cl}, 6-\mathrm{Mc}$ & $5-\mathrm{Mc}$ & 1.455 & 1.6588 & 1.9445 \\
\hline 47 & $2,4,6-\mathrm{Mc}_{3}$ & 3,5-di-Me & 1.77 & 1.9448 & 0.9218 \\
\hline 48 & $2-\mathrm{Cl}, 6-\mathrm{Mc}$ & 6-... $\mathrm{NH}_{2}$ & 2.699 & 1.8113 & 2.5349 \\
\hline 49 & 2-Cl,6-Mc & 6-CH $3-\mathrm{N}-(\mathrm{Mc})_{2}$ & 2 & 2.4422 & 2.3141 \\
\hline 50 & 2-Cl,6-Mc & 6- $\mathrm{CH}_{2}$-Morpholinyl & 1.886 & 2.473 & 2.4941 \\
\hline 51 & $2-\mathrm{Cl}, 6-\mathrm{Mc}$ & $6-\mathrm{NH}-\left(\mathrm{CH}_{2}\right)_{2} \mathrm{OH}$ & 3.301 & 2.432 & 2.6512 \\
\hline 53 & $2-\mathrm{Cl}, 6-\mathrm{Mc}$ & $6-\mathrm{NH}-\mathrm{CH}_{2} \mathrm{C}\left(\mathrm{CH}_{3}\right)_{3} \mathrm{NH}_{2}$ & 2.222 & 2.3898 & 2.6447 \\
\hline 54 & $2-\mathrm{Cl}, 6-\mathrm{Mc}$ & 4-Mc & 1.699 & 1.6687 & 1.946 \\
\hline \multirow[t]{2}{*}{55} & $2-\mathrm{Cl}, 6-\mathrm{Mc}$ & 4.6-di-Mc & 2.096 & 1.7679 & 1.9672 \\
\hline & & TEST SET & & & \\
\hline 45 & $2,4,6-\mathrm{Mc}_{3}$ & 5-Mc & 1.142 & 1.2159 & 1.1718 \\
\hline 52 & $2-\mathrm{Cl}, 6-\mathrm{Mc}$ & 6-Mc & 2.045 & 1.7737 & 1.9683 \\
\hline
\end{tabular}

"Observed attivities. "VFA predicted activities. "RSA predicted altivities

The ATP binding site, which was filled with A.NP (phosphoaminophosphonic acid-adenlate ester) in the X-ray structure, was used to define active site region. Active site radius was taken as 10.0 $\AA$ around ANP molecule. The RMS deviation was considered within $1.5 \AA$ and annealing paraneter of van der Waals interaction was 4.0 , hydrogen bond interaction was 2.5 .

\section{Results and Discussion}

Molecular Field Analysis (MFA). From the given training set, a MFA model was developed with $r^{2}$ value of 0.83 , a cross-validated $r^{2}$ value of 0.764 , and with a PRESS (Predictive Sum of Squares) value of 12.2. The correlation between experimental and predicted pIC 50 values is shown in Figure 2a. MFA model was validated by test set comprising of 15 molecules, which are shown in Table 1-4. The steric $(\mathrm{CH} 3)$ and electrostatic $(\mathrm{H}+)$ descriptors in the QSAR equation of MFA (eq. 1) specify the regions where variations in the structural features (steric or electrostatic) of different compounds in the training set, lead to increased or decreased activities. The number accompanying descriptors, in equation 1 represents its position in the three-dimensional MFA grid.

$$
\begin{aligned}
& \text { Aclivily - - } .00604 \\
& -0.059054 * \text { *CII3/406" } 10.039039 * \text { *Il 1/557" } \\
& 10.027846 \text { * "H I } / 278 \text { " } 0.043972 * \text { "I] } / 174 \text { " } \\
& 10.030442 * \text { "CI 13/368" }
\end{aligned}
$$

The equation generated by MFA, predicted accurately for test set compounds $18,21,40,45,52,57,59,62$ and 69 , predicted moderately for compounds $8,13,28,35$ and 36 . The only compound whose activity was abnormally predicted was compound 22 . This might be due to the presence of $\mathrm{CH}_{2} \mathrm{OH}$ group on the 4th position of phenyl group of anilide. 
Table 4. Training set and test set compounds with observed and predicted activities

\begin{tabular}{|c|c|c|c|c|c|}
\hline Compound & $\mathrm{R}$ & RI & Г:xp. pIC50 ${ }^{\prime \prime}$ & MFA Pred, plC50 & RSA Pred. plC $50^{\circ}$ \\
\hline 56 & $2,4,6-\mathrm{Mc}_{3}$ & 2,6-di-Mc & 1.275 & 1.3604 & 1.0677 \\
\hline 58 & $2-\mathrm{Cl}, 6-\mathrm{Mc}$ & $2-\mathrm{Cl}$ & 1.508 & 1.7135 & 1.576 \\
\hline 60 & $2-\mathrm{Cl} .6-\mathrm{Mc}$ & $6-\mathrm{NHCH}_{2} \mathrm{CH}_{2} \mathrm{OH}$ & 2.096 & 1.7547 & 1.7605 \\
\hline 61 & $2-\mathrm{Cl}, 6-\mathrm{Mc}$ & 2,6-di-Mc & 1.699 & 1.8461 & 1.799 \\
\hline 63 & $2-\mathrm{Cl}, 6-\mathrm{Mc}$ & 6-Et & 2.301 & 1.7102 & 1.7652 \\
\hline 64 & $2-\mathrm{Cl}, 6-\mathrm{Mc}$ & 2- $\mathrm{NHCH}, \mathrm{CH}_{2} \mathrm{OH}, 6-\mathrm{Mc}$ & 2.699 & 2.3935 & 2.4031 \\
\hline 66 & $2-\mathrm{Cl}, 6-\mathrm{Mc}$ & 2-NHCH$, \mathrm{C}\left(\mathrm{CH}_{3}\right), \mathrm{OH}, 6-\mathrm{Mc}$ & 2.222 & 2.3856 & 2.4039 \\
\hline 67 & 2-Cl.6-Mc & $\begin{array}{r}\text { 6-NHCH} \\
\text { TEST SET }\end{array}$ & 2.699 & 2.5175 & 2.6717 \\
\hline 57 & $2,4,6-\mathrm{Mc}_{\mathrm{i}}$ & 6-Et & 1.113 & 1.2181 & 0.9926 \\
\hline 59 & 2-C],6-Mc & 6-Cl & 1.699 & 1.716 & 1.7609 \\
\hline 62 & 2-C],6-Mc & $2-\mathrm{NHCH}_{2} \mathrm{CH} \cdot \mathrm{OH}$ & 2.523 & 2.4227 & 2.404 \\
\hline 65 & $2-\mathrm{Cl}, 6-\mathrm{Mc}$ & 6-Mc & 1.678 & 1.707 & 1.7652 \\
\hline
\end{tabular}

"Observed activitics. "MГ^ predicted activities. "RSA predicted aclivilies

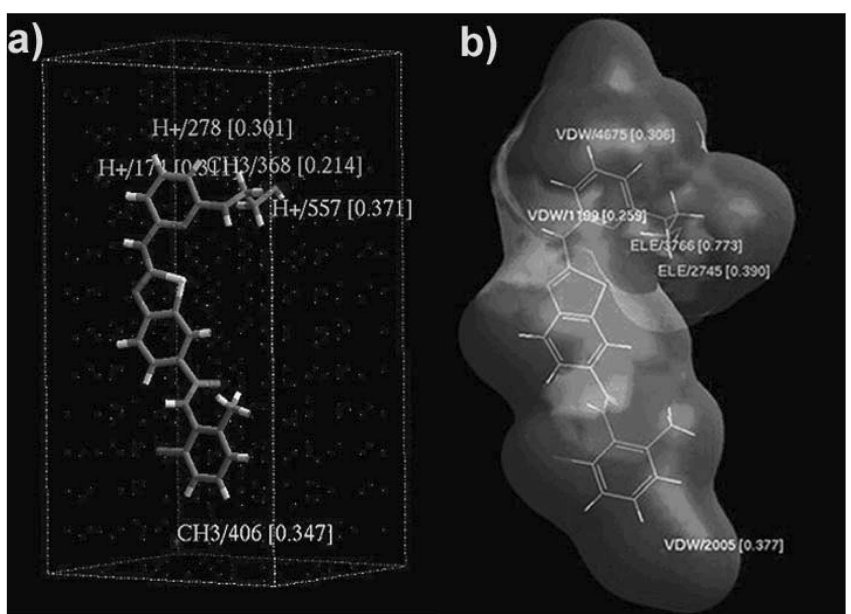

Figure 1. MFA grid and grid points (a) and RSA pseudo receptor surface (b) with high active compound $5 I$.

As there were no other compounds with such groups at 4th position in training set the prediction might be bad.

The presence of $\mathrm{CH} 3 / 406$ at the meta position of anilide group gave a negative effect on the equation which means the presence of steric/bulky groups is unfavorable (shown in Figure 1a). This is evident from the low activity of compounds 5g, 5k (>12.5 $\mathrm{uM})^{19}$ which have methyl and

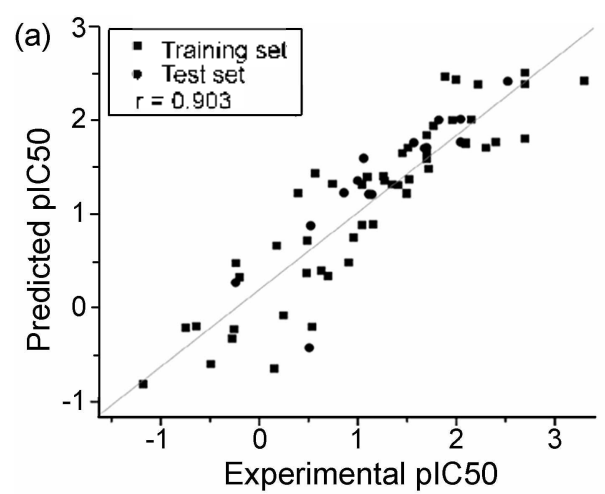<smiles>Cc1cc(C)c(NC(=O)c2ccc3nc(NC(=O)OC(C)(C)C)sc3c2)c(Br)c1[18OH]</smiles><smiles>Cc1cc(C)c(OCC(C)(C)C)c(Br)c1NC(=O)c1ccc2nc(NC(=O)OC(C)(C)C)sc2c1</smiles><smiles>Cc1ccc(C(C)C)c(C)c1NC(=O)c1ccc2nc(NC(=O)OC(C)(C)C)sc2c1</smiles><smiles>Cc1cccc(C)c1NC(=O)c1ccc2nc(NC(=O)OC(C)(C)C)sc2c1</smiles>

Comp-32 (IC50=0.09uM)

Figure 3. Negalive elfecl of bulky groups (C13/406) at the meta position (shown with asterisk) of anilide group.

isopropyl groups at meta position when compared to compound 29 and compound 32 respectively (Figure 3 ). The presence of $\mathrm{H}+/ 557$ group at the 6 th position of pyridine or 2nd position of pyrimidine favors the presence of electrostatic groups on the aliphatic group. This is also evident from the fact that the compound $6 \mathbf{a a},{ }^{20}$ which is not having any group on 6th position of pyridine ring ( $\mathrm{plC} 50=1.075$ ) is

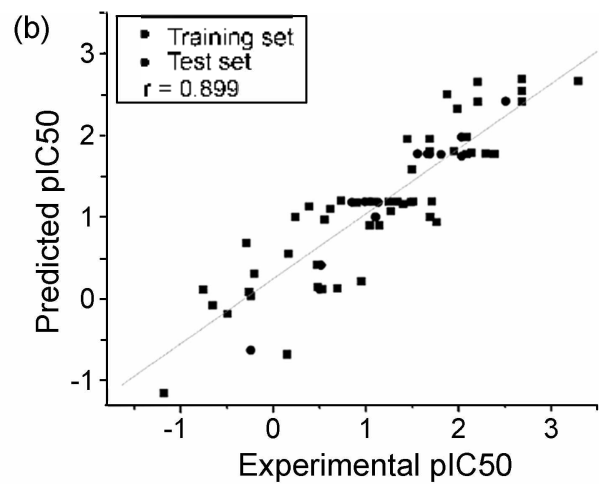

Figure 2. Correlation graph between experimental and predicted activities of MFA (a) and RSA (b). 


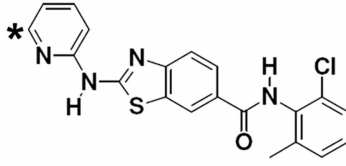

Comp-6aa (plC50=1.075)<smiles>Cc1cccc(Cl)c1NC(=O)c1ccc2nc(Nc3ccc[14c]([14CH3])n3)sc2c1</smiles>

Comp-53 (plC50 $=2.222)$

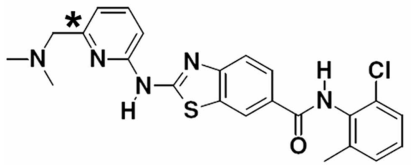

Comp-49 (plC50=2)
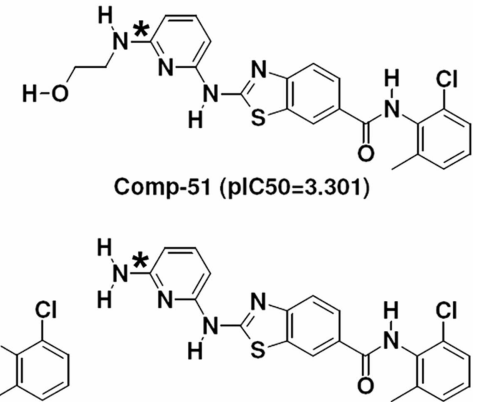

Comp-48 (pIC50=2.699)

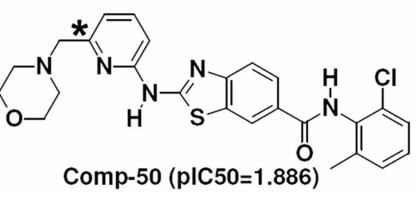

Figure 4. Requirement of electrostatic groups $(\mathrm{H}-1557)$ at the 6 th position (shown with asterisk) of pyridine ring.

relatively low active than compounds $51,48,53,49$ and 50 which have electrostatic group (Figure 4). In a similar manner the compound 40, which does not have any electrostatic group on 2nd position of pyrimidine ring (pIC50 = 1.569 ) is less active than compound 64,62 and 66 . This is also supported by the formation of a hydrogen bond with Ser 323 by compound 51 as shown in Figure $7 \mathrm{a}$. This suggests that the electrostatic group at 6ih position of pyridine or 2nd position of pyrimidine is erucial for hydrogen bond formation.

The presence of $\mathrm{H}+/ 278$ at 4 th position of pyridine or $6 \mathrm{th}$ position of pyrimidine suggests that electrostatic groups on aliphatic chain or heterocyclic groups would enhanee the activily. This explanation can be supported by the high activity of compounds 6ah (pIC50 $=2.045$ ), ${ }^{211}$ 6ai and 6aj $(\mathrm{pIC} 50=3.000 \mathrm{for} \text { both })^{20}$ which have electrostatic groups
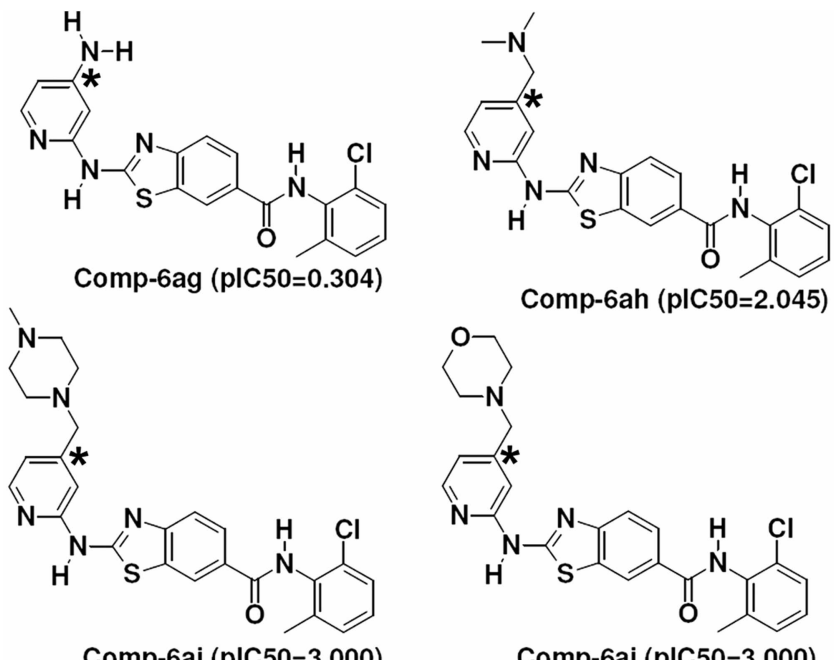

Figure 5. Requirement of electrostatic $(\mathrm{H}-278)$ groups on aljphatic or heterocyclic rings al th position (shown with asterisk) of pyridine ring. on aliphatic and heterocyclic groups respectively at 4 th position of pyridine than compound 6ag $(\mathrm{pIC} 50=0.304)^{20}$ which has amino group at 4th position (Figure 5).

Receptor Surface Analysis (RSA). RSA model with $r^{2}$ value of 0.796 , a cross-validated $r^{2}$ value of 0.706 , and with a PRTSS value of 15.17 was developed. The correlation between experimental and predicted pIC 50 values is given in Figure $2 b$. RSA model was validated by the same lest set which was used in the MFA comprising of 15 molecules as shown in Table 1-4. The van der Waals (VT)W) and electrostatic (ГL.Г) descriptors in the QSAR equation of RSA (cq. 2) specify the regions where variations in the struetural features (steric or electrostatic), of different compounds in the training set, lead to increased or decreased activities with respect to the pseudo receptor surface generaled.

$$
\begin{aligned}
& \text { Activity }=0.708798 \\
& +6.21263 \text { *VDW/1 } 199 "+4.04185 * \text { "ELE/2745" } \\
& +7.21059 \text { * "VDW/4675"+7.94388 * "VDW/2005" } \\
& -8.30589 \text { * "ELE/3766" }
\end{aligned}
$$

The RSA equation generated predieted well for all test set compounds except for compound 21, 22, 35 and 36. The presence of VT)W/4675 at the 4 th position of pyridine ring strongly favors a bulky group (Figure 1b). Results of MFA suggested that electrostatic groups alone were unfavorable compared to electrostatic groups on aliphatic chain or heterocyclic rings. This coincides and strongly recommends the presence of bulky moieties with charged groups. This can be evideneed by the compound 6aa (pIC50 $=1.075)<$ compound $54(\mathrm{pIC} 50=1.699)<$ compound 6 ah $(\mathrm{pIC} 50=$ 2.045).

The presence of ГLL.Г/2745 near the 6th position of pyridine or 2nd position ol pyrimidine favors the presence of electrostatic groups. This was also predicted by MFA model. The presence of VDW/2005 at the para position of anilide group gave a positive eflect on the equation which means the presence of bulky groups is favorabli.

Molecular Docking. GOLD fitness scores were compared

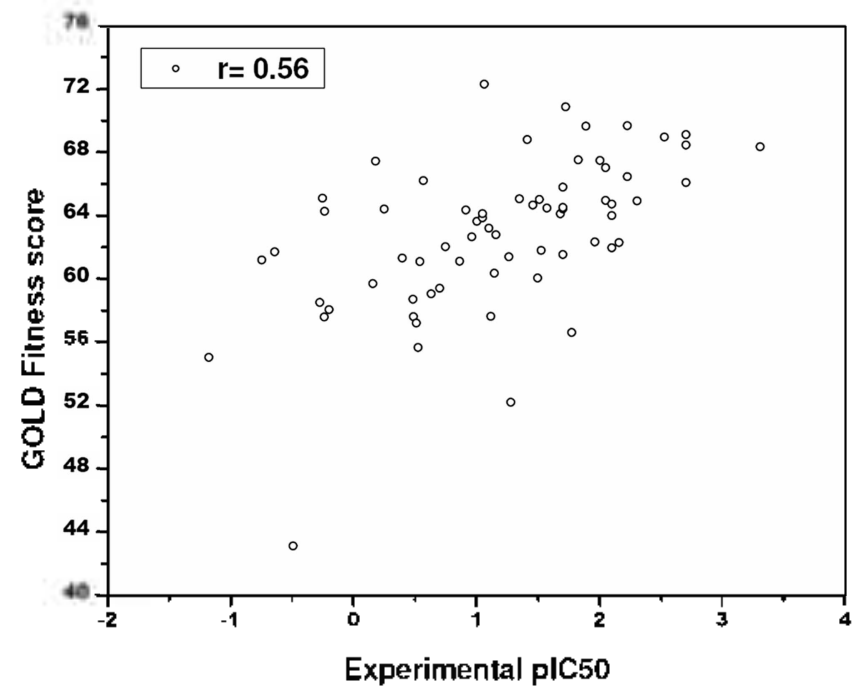

Figure 6. Plot of fitness score against measured pIC50. 
Table 5. Comparison of GOLD predicted Fitness scores and Experimental activities

\begin{tabular}{lccc}
\hline & $\begin{array}{c}\text { Pred. } \\
\text { high } \\
\text { active }\end{array}$ & $\begin{array}{c}\text { Pred. } \\
\text { moderately } \\
\text { active }\end{array}$ & $\begin{array}{c}\text { Pred. } \\
\text { Low } \\
\text { active }\end{array}$ \\
\hline Exp. high active compounds & 13 & 5 & 0 \\
Exp. moderately active compounds & 4 & 19 & 5 \\
Exp. low active compounds & 3 & 6 & 12 \\
\hline
\end{tabular}

Comelation between the number of compounds with high. moderate and low $G O L D$ predictive score and the number of compounds with high, moderate and low experimental activity values respectively.

with observed activity for all 67 molecules. The correlation graph (Figure 6) drawn between observed activities and GOLD predicted fitness scores, gave correlation $\mathrm{r}=0.56$. All molecules shown in Table 1 to Table 4 were divided into three sets named low active ( $\mathrm{pIC} 50$ from -1.178 to 0.698 ). moderately active (pIC50 from -0.7 to 1.8 ) and high active (pIC50 from 1.8 to 3.301 ) based on experimental pIC50 values. Total numbers of low active compounds are 21 , moderately active compounds are 28 and 18 high active compounds. After performing docking, these three categories fell in the regions of 43-60, 61-64 and 65-70 GOLD fitness scores respectively with few discrepancies.

The predictive ability of GOLD fitness scores are shown in Table 5. Out of 18 high active compounds set, 13 compounds were predicted as high active and remaining 5 compounds as moderately active. No highly active compound was predicted as low active. Out of 28 moderately active compounds set, 19 compounds were predicted as moderately active, 4 as highly active and 5 as low active. Among the 21 low active compounds set, 12 were predicted as low active, 6 were predicted as moderately active while 3 were predicted as highly active.

Compound 19 (Table 1) is experimentally low active but $G O L D$ predicted as high active, as its structure is similar to compound 18 which had experimentally high activity and high predicted score. The only structural difference is the presence of isopropyl group at Rl substitution instead of cyclopropyl group. As both are aliphatic hydrophobic groups with less structural difference GOLD predicted fitness score predicted a low active compound 19 as highly active. The other two compounds 24 and 25 (Table 1) are expermentally low active but GOLD predicted as high active, as they had similar structure with compound $\mathbf{2 1}$ which is experimentally high active as well as high GOLD predicted score. The only structural difference between them is the presence of cyclopropyl (compound 21) group at R1 substitution instead of cyclobutyl (compound 24) group and 2-tetrahydrofuryl (compound 25) group. Due to less structural difference, GOLD predicted fitness score showed these two compounds as high active. Predicted fitness scores for high and low active compounds are shown in Table 6.

The protein ligand interactions were evaluated based on hydrogen bond distances (Figure 7). Both best-ranked conformations of high and low active compounds (compound 51 and 34 respectively) were used for measuring hydrogen bond interactions. Compound $\mathbf{5 1}$ formed four different hydrogen interactions with active site anmo acids (Figure $7 \mathrm{a}$ ). The $\mathrm{NH}$ of aniline fommed hydrogen bond with hydroxyl group of Thr316, the benzothiazole nitrogen fomed $\mathrm{H}$-bond with Met319 amino group, $\mathrm{NH}$ group of amino-pyridine is hydrogen bonded to carbonyl group of Met319, the hydroxyl group present in the 6th position of amino-pyridine ring formed hydrogen bonding with Ser323 amino group. The hydrogen bond distances are $1.94,1.91,2.06$, and $2.24 \hat{\mathrm{A}}$, respectively, Some hydrogen atoms present on benzothiazole ring $(\mathrm{C}-\mathrm{H})$ may form weak hydrogen interactions with other active site amino acids.

The hydrogen bonding interactions with the least active molecule (compound 34) were also observed (Figure 7b). The $\mathrm{NH}$ of aniline fomed hydrogen bond with hydroxyl group of Thr316, the benzothiazole nitrogen fomed $\mathrm{H}$-bond contact with Met319 amino group. The amino group of benzothiazole fomed hydrogen bond with carbonyl group of Met319. The hydrogen bond distances are $2.31,2.41$, and $2.30 \hat{A}$, respectively. All the three $\mathrm{H}$-bond interactions are weak relative to compound 51. The predicted protein-ligand hydrogen bond energy (extemal H-bond) for compound $\mathbf{3 4}$ is 0.19 , which is very low when compared to other compounds as well as highly active compound 51 (6.3).
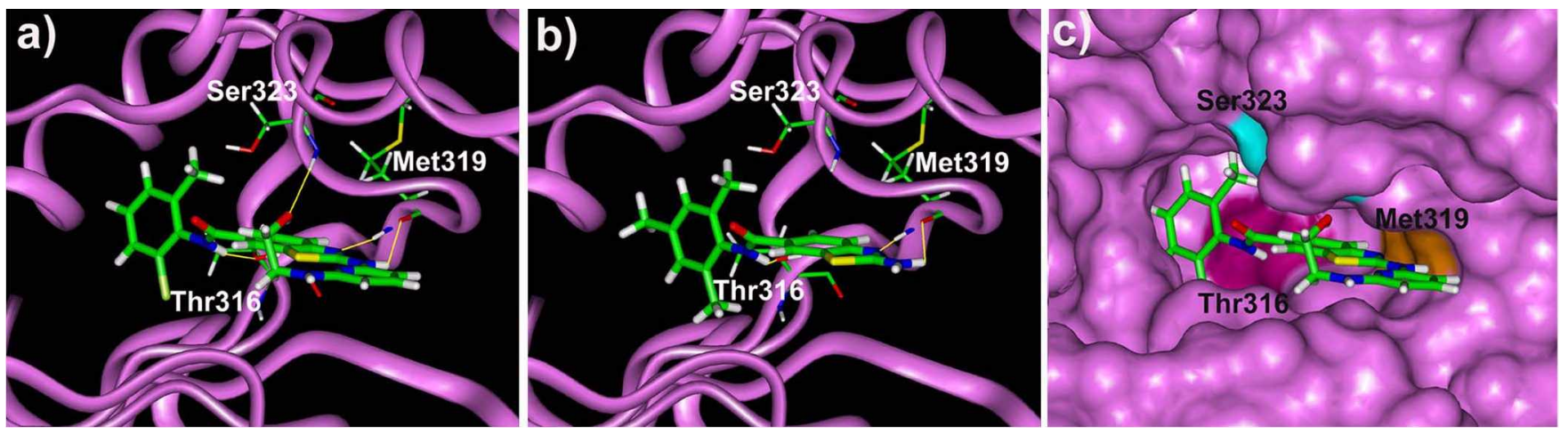

Figure 7. Molecular docking results: ligand and active site interaction. Hydrogen bonds between the ligand and the three key amino acids in active site were displayed by yellow line: compound 51 (a) and compound 34 (b). The binding pocket of P56 LCK was shown with a docked ligand, compound 51. 
Table 6. GOLD predicted fitness scores for high active compound $\$ 1$ and low active compound 34

\begin{tabular}{cccccc}
\hline $\begin{array}{c}\text { \#File } \\
\text { name }\end{array}$ & Fitness & $\begin{array}{c}\text { VDW } \\
\text { int }\end{array}$ & $\begin{array}{c}\text { Tors } \\
\text { int }\end{array}$ & $\begin{array}{c}\text { VDW } \\
\text { ext }\end{array}$ & $\begin{array}{c}\text { H } \\
\text { ext }\end{array}$ \\
\hline Comp 34 & 55.04 & -0.22 & -8.36 & 46.12 & 0.19 \\
Comp 51 & 68.34 & -1.87 & -14.51 & 57.03 & 6.3 \\
\hline
\end{tabular}

VDW int (Ligand intemal van der Waal energy); Tors int (Ligand torsional strain energy); VDW ext (Protein-ligand van der Waal energy); II ext (Protein-ligand hydrogen bond energy) were compared

Van der waals interactions have also played an important role at the active site. This can be supported by citing a comparison between the inactive compound which has no groups attached to the 2-amino position of benzothiazole and the active compound or others that had aromatic/ aliphatic/alicyclic groups. These groups exhibit van der waals interactions at the active site region. Fitness scores with their individual scores are represented in Table 6. Finally, the binding pocket of the active site was visualized with the docked ligand in Figure $7 \mathrm{c}$.

\section{Conclusions}

In this work, 3D-QSAR and molecular docking studies were carried out to explore the binding mechanism of 2amino-benzothiazole-6-anilide derivatives to the P56 LCK. and to construct highly predictive $3 \mathrm{D}-\mathrm{QSAR}$ models for designing new lymphocyte-specific protein tyrosine kinase inhibitors for the treatment of auto-immune diseases. The presence of bulky groups at the meta position of anilide group gave a negative effect on activity of the molecule. The presence of electrostatic groups on aliphatic chain or heterocyclic rings at the 4th position of pyridine and 6th position of pyrimidine ring is strongly favored both in RSA and MFA models. GOLD method was used for molecular docking of 67 betzothiazole derivatives at P56 LCK ATP binding site. GOLD predicted fitness scores correlated well with experimental activity. Thus GOLD molecular docking and 3D-QSAR methods provided new guidelines for novel inhibitor design to accelerate the drug discovery process.

Acknowledgements. Nagakumar Bharatham and Kavitha Bharatham thank their parents for support and encouragement. And they are also thankful to D. D. Rami Reddy for his guidance. Those two authors were recipients of fellowships from the BK21 Programs. This work was supported by grants from the MOSTKOSEF for the Enviroumental Biotechnology National Core Research Center (grant \#: R15-2003-012-02001-0) and for the Basic Research Program (grant \#: R01-2005-000-10373-0).

\section{References}

1. Isakov, N.; Biesinger, B. Eur. J. Biochem, 2000, 267, 3413.

2. Levitzki, A. Pharmacol. Ther: 1999, 82,231 .

3. Aaronson, S. A. Science 1991, 254, 1146.

4. Neet, K.; Hunter, T. Genes Cells 1996, l, 147.

5. Robinson, D. R.; Wu, Y. M.; Lin, S. F. Oncogene 2000, 19, 55.48.

6. Gu, J.; Gu, X. Gene 2003,3/7, 49.

7. Marth, J. D.; Peet. R.; Krebs, E. G.; Perlmutter, R. M. Cell 1985. $43,393$.

8. Voronova, A. F.: Sefton, B. M. Nature 1986, 3/9, 682.

9. Veillette, A.; Abraham, N.; Caron, L.; Davidson, D. Senin. Inmmtmol 1991, 3, 143.

10. Biondi, A.; Paganin, C.; Rossi, V.; Benvestito, S.; Perlmutter, R. M.; Mantovani, A.; Allavena. P. Ettr. J. Inmmtrol. 1991, 21, 843 .

11. Bolen, J. B.: Brugge, J. S. Annti Rer: Inthinol. 1997, 15, 37 I.

12. Trevillyan, J. M.; Chiou, X. G.: Ballaron, S. J.; Tang, Q. M.; Buko, A.: Sheets, M. P.: Smith, M. L.; Putman, C. B.: Wiedeman, P.: Tu, N.: Madar, D.: Smith, H. T.: Gubbins, E. J.: Warrior, U. P.: Chen, $\checkmark$. W.; Mollison, K. W.; Faltynek, C. R.; Diuric, S. W. Arch. Biochem. Biophys, 1999, 364, 19.

13. Palacios, E. H.; Weiss, A. Oncogere 2004, 23, 7990.

14. Vang, T.; Abrahamsern, H.: Myklebust, S.; Enserink, J.: Prydz, H.: Mustelin, T.: Amarzguioui, M.: Tasken, K. Eur J. Inmmol. 2004 , $34,2191$.

15. Liu, P.; Aitken, K.; Kong, Y. Y.; Opavsky, M. A.; Martino, T.; Dawood, F.; Wen, W. H.; Kozieradzki, I.; Bachmaier, K.; Straus, D.; Mak, T. W.; Penninger, J. M. Nat. Med. $2000,6,429$.

16. Llinas-Brunet, M.; Beaulieu, P. L.; Cameron, D. R.; Ferland, J. M.: Gauthier, J.: Ghiro, E.; Gillard, J.: Gorys, V.; Poirier, M.: Rancourt, J.: Wernic, D.: Betageri, R.; Cardozo, M.: Jakes, S.: Lukas, S.; Patel, U.; Proudfoot, J.; Moss, N. J. Med. Chen. 1999, 42,722 .

17. Hanke, J. H.; Pollok, B. A.; Changelian, P. S. Inflamm, Res. 1995, $44,357$.

18. Goldberg, D. R.: Butz, T: Cardozo, M. G.: Eckner, R. J.: Hammach, A.: Huang, J.: Jakes, S.; Kapadia, S.: Kashem, M.: Lukas, S.; Monwick, T. M.; Panzenbeck, M.; Patel, U.; Pav, S.; Peet, G. W.; Peterson, J. D.; Prokopowicz, A. S.; Snow, R. J.; Sellati, R.; Tahahashi, H.; Tan, J.; Tschantz, M. A.; Wang, X. J.; Wang, Y.: Wolak, J.; Xiong, P.; Moss, N. J. Med. Chem. 2003, 46, 1337.

19. Das, J.: Lin, J.: Moquin, R. V.; Shen, Z.: Spergel, \$. H.; Wityak, J.: Doweyko, A. M.; DeFex, H. F.; Fang, Q.; Pang, S.; Pitt S.; Shen, D. R.; Schieven, G. L.; Barrish, J. C. Bioorg. Med. Chem. Lett. $2003,13,2145$.

20. Das, J.; Moquin, R. V.: Lin, J.: Liu, C.: Doweyko, A. M.: DeFex, H. F.: Fang, Q.; Pang, S.; Pitt, S.; Shen, D. R.; Schieven, G. L.: Barrish, J. C.: Wityak, J. Bioorg. Med. Chem. Lett. 2003, 13, 2587.

21. Lee, K. W.; Kwon, S. Y.; Hwang, S.; Lee, J.-U.; Kim, H. Bull Korear Chem, Soc, 1996, 77,147 .

22. Hyun, K. H.; Kwack, I. Y.; Lee, D. Y.; Park, H. Y.; Lee, B.-S.; Kim, C. K. Bull. Korean Chem. Soc. 2004, $25,1801$.

23. Cerizs 2 A program Suite for Molecular Modelling Activities: Molecular Simulations: Scranton Raod, San Diego, CA 921213752 , USA. (http://wwwiaccelrys.com)

24. Jones, G; Willett, P.; Glen, R. C.; Leach, A. R.; Taylor, R. J. Mol Biol. 1997, 267, 727.

25. Zhu, X.: Kim, J. L.: Newcomb, J. R.; Rose, P. E.: \$lover, D. R.: Toledo, L. M.: Zhao, H.; Morgenstern, K. A. Structure Fold Des. $1999,7,651$. 